\title{
СОВРЕМЕННАЯ ТРОМБОЛИТИЧЕСКАЯ ТЕРАПИЯ У БОЛЬНЫХ \\ С ПРИЗНАКАМИ ОСТРО ВОЗНИКШЕЙ ОККЛЮЗИИ КОРОНАРНОЙ АРТЕРИИ
}

\author{
Быстрое, полное и стойкое восстановление кровотока по коронарной артерии (реперфузионная \\ терапия) - основа лечения больных с сохраняющейся острой тромботической окклюзией крупного \\ сосуда, кровоснабжающего миокард, в типичном случае приводящей к возникновению затяжного \\ ангинозного приступа и достаточно продолжительных (обычно более 20 мин) подъемов \\ сегмента ST на ЭКГ [1-5].
}

Ключевые слова: тромболитическая терапия, окклюзия коронарной артерии, чрескожное коронарное вмешательство

\section{СПОСОБЫ РЕПЕРФУЗИОННОГО ЛЕЧЕНИЯ}

Хорошо установлено, что внутривенное введение фибринолитика и пероральный прием ацетилсалициловой кислоты позволяют существенно уменышить вероятность неблагоприятного течения заболевания, и эффект значительно возрастает при их совместном применении. Так, в наиболее крупном из проведенных плацебо-контролируемых клинических исследований ISIS-2, включавшем 17187 больных с подозрением на острый инфаркт миокарда (ИМ), введение стрептокиназы приводило к достоверному снижению риска сосудистой смерти в ближайшие 5 нед. на 23\%, что соответствовало предотвращению 24 неблагоприятных исходов на каждую тысячу леченых [6]. При сочетании стрептокиназы с ацетилсалициловой кислотой эффективность лечения удваивалась. Достигнутый әффект сохранялся на протяжении многих лет [7]. Кроме того, у получавших сочетание стрептокиназы с ацетилсалициловой кислотой реже возникали рецидивы инфаркта миокарда и отмечалось меныше случаев остановки кровообращения (на 11 и 25 на каждую тысячу леченых больных соответственно).

По совокупным данным контролируемых исследований, включавших более 1 тыс. больных с подозрением на острый ИМ (в целом 58600 человек), тромболитическая терапия с использованием стрептокиназы или эквивалентных ей по эффективности режимов введения других препаратов способна предотвратить 18 смертей на каждую тысячу леченых больных [8]. Это благоприятное влияние не зависит от пола, возраста, величины АД (если систолическое АД не превышало 180 мм рт. ст.), ЧСС, наличия или отсутствия ИМ в анамнезе, сахарного диабета и по абсолютной величине (числу предотвращенных смертей на каждую тысячу леченых больных) выше у пациентов с высоким риском неблагоприятного исхода. При надлежащем отборе больных польза тромболитической терапии намного превосходит опасность геморра- гических осложнений: по совокупным данным, на каждую тысячу леченых ожидается возникновение 4 дополнительных инсультов (из них 2 смертельных, 1 инвалидизирующего и 1 неинвалидизирующего) и примерно 7 серьезных внечерепных кровотечений (включая угрожающие жизни и требующие переливания крови).

Эффективность реперфузионной терапии критически зависит от времени начала лечения. При этом наиболее важны первые 2-3 ч от начала симптомов, когда некротизируется максимальный объем жизнеспособного миокарда. Так, по совокупным данным 22 рандомизированных контролируемых клинических исследований, включавших в совокупности 50246 человек, введение стрептокиназы или эквивалентных ей по эффективности режимов тромболитической терапии в первый час после возникновения заболевания за 35 сут. позволяло предотвратить 65 случаев смерти на каждую тысячу леченых больных [8, 9]. При начале лечения через $\geq 1-2$ ч эта цифра составила 37 , через $\geq 2-3$ ч -26 , через $\geq 3-6$ ч - 29, а через $\geq 6-12$ ч - 18. Снижение риска смерти, составлявшее 48\% при начале лечения в первый час заболевания и 44\% при начале лечения в первые 2 ч, при более позднем вмешательстве уменьшалось до 20\% ( $p=0,001)$ [9]. Основываясь на приведенных фактах, эксперты Американской ассоциации сердца и Коллегии кардиологов в 2007 г. констатировали, что у больных с признаками стойкой окклюзии коронарной артерии (развивающимся ИМ с подъемами сегмента ST на ЭКГ) следует стремиться к максимально раннему началу реперфузионного лечения и общее время ишемии миокарда не должно превышать 2 ч [3]. При этом очевидно, выбор в качестве контроля качества лечения времени задержек в стационаре («от двери до иглы» и «от двери до баллона») с этой точки зрения неадекватен [10]. Отсчет времени в настоящее время рекомендуют начинать от первого контакта с медицинским персоналом (прибытия бригады неотложной помощи или самостоятельного обращения в стационар) [4, 5]. Естественно, что минимальная задержка реперфузионной терапии ожидается в случаях, когда фибринолитик вводится догоспитально. Доказано, что этот выигрыш во времени сказывается на әффективности лечения. 
Так, в рандомизированных контролируемых исследованиях, включавших в совокупности более 6500 больных в сроки не позднее 6 ч от начала заболевания, догоспитальная тромболитическая терапия давала возможность начать лечение в среднем на 60 мин раньше, чем начало введения фибринолитика в стационаре. В результате удалось дополнительно предотвратить примерно 16 смертей на каждую тысячу больных за время лечения в стационаре и 21 в ближайший месяц [11-13]. Данная закономерность подтверждается и в более широкой клинической практике, и есть свидетельства, что в первые часы ИМ догоспитальная тромболитическая терапия может конкурировать по эффективности с первичным чрескожным коронарным вмешательством (ЧКВ) [14-18].

Первичное (прямое) ЧКВ обладает несомненным клиническим преимуществом перед тромболитической терапией, начатой в стационаре. Так, по совокупным данным, инвазивный подход способствует дополнительному снижению риска смерти на 30\%, несмертельного рецидива ИМ на 58\%, позволяет предотвратить 20 и 40 таких событий на каждую тысячу леченых больных соответственно [19]. При этом меныше также частота внутричерепных кровотечений. Такое преимущество проявляется в ближайшие 4-6 нед. и сохраняется долгое время. Однако дополнительное положительное воздействие инвазивного лечения на смертность может заметно уменышиться при слишком выраженной задержке во времени между началом тромболитической терапии и механическим восстановлением просвета сосудистого русла (раздувании баллона в окклюзированной коронарной артерии). Так, один из метаанализов рандомизированных клинических исследований показал, что преимущество первичного ЧКВ по влиянию на смертность утрачивается, если подобная задержка превышает 60 мин [20]. Однако результаты другого метаанализа не исключают, что приемлемы и большие задержки до начала инвазивного лечения [21]. В настоящее время первичное ЧКВ считается предпочтительным, если может быть осуществлено не позднее чем через 90-120 мин после контакта с медицинским персоналом $[1,4,5]$. Кроме того, преимущество первичного ЧКВ перед тромболитической терапией реализуется, только когда процедура выполняется в надлежащих условиях (достаточно опытным специалистом в лечебном учреждении с достаточно частым выполнением подобных вмешательств) [22, 23].

Как уменьшить неизбежную задержку во времени начала лечения при использовании ЧКВ по сравнению с фибринолитиком, доступным уже у постели больного после прибытия бригады неотложной помощи? Очевидно, это требует совершенствования подходов к оказанию помощи больным острым коронарным синдромом в целом. Предлагают следующие мероприятия: увеличить число центров, обладающих возможностью инвазивного лечения и необходимой квалификацией, доступных большинству населения определенной территории в приемлемые сроки (с учетом особенностей функционирования транспортной системы); выявлять показания к реперфузионному лечению догоспитально (после регистрации ЭКГ) с последующим оповещением специалистов ангиографической лаборатории и началом ее подготов- ки во время транспортировки; транспортировать больного в стационар, располагающий достаточным опытом инвазивного лечения, минуя другие лечебные учреждения; организовать систему ускоренного продвижения пациента в пределах стационара $[4,5,10]$. Тем не менее даже в США, где указанные усилия предпринимаются достаточно давно, только 20\% популяции проживают на территориях, где есть возможность в ближайшие 90 мин оказаться в медицинском учреждении, обладающем возможностями выполнения ЧКВ [10].

Очевидно, что, если инвазивное лечение невозможно, сопряжено со значительной задержкой во времени или не может быть выполнено в надлежащих условиях, необходимо ввести фибринолитик и в последующем вновь рассмотреть вопрос о необходимости реваскуляризации миокарда $[1,4,5]$. При этом в настоящее время речь идет не только о случаях неэффективности тромболитической терапии, но и о повсеместном (поголовном) выполнении коронарной ангиографии (как правило, с последующим стентированием инфаркт-связанного стеноза) в первые сутки после тромболитической терапии, в т. ч. у больных с неинвазивными свидетельствами реперфузии миокарда («фармакоинвазивный» подход) $[4,5]$.

\section{Тромболитическая терапия с использованием стрептокиназы или эквивалентных ей по эффективности режимов введения других препаратов способна предотвратить 18 смертей на каждую тысячу леченых больных}

Таким образом, поскольку фибринолитическая терапия остается самым распространенным и для многих больных единственно доступным способом своевременного реперфузионного лечения, особое значение приобретает совершенствование подходов к ее выполнению, чтобы добиться наибольшей эффективности при наименьшем риске геморрагических осложнений. В настоящее время международным сообществом при остром коронарном синдроме со стойкими подъемами сегмента ST на ЭКГ рекомендованы стрептокиназа, алтеплаза, тенектеплаза и ретеплаза (последняя в РФ не зарегистрирована); начать их введение необходимо в первые 30 мин после контакта с медперсоналом [4-5].

Клиническое преимущество фибрин-специфичного фибринолитика алтеплазы перед стрептокиназой было продемонстрировано в 1993 г., когда появились результаты крупнейшего рандомизированного сравнительного исследования GUSTO-1, включавшего 41021 больного, госпитализированного в первые 6 ч ИМ с подъемами сегмента ST на ЭКГ [24]. 1,5-часовое внутривенное введение алтеплазы в сочетании с инфузией НФГ на протяжении как минимум 48 ч по сравнению со стрептокиназой позволяло достоверно уменьшить риск смерти на 14\%, причем преимущество проявлялось уже в первые сутки после начала лечения и сохранялось при длительном наблюдении [25]. В итоге удалось дополнительно предотвратить 10 смертельных исходов на каждую тысячу леченых больных ценой возникновения примерно 2 гемор- 
рагических инсультов. У получавших алтеплазу достоверно реже возникали умеренные кровотечения и аллергические реакции. Кроме того, течение заболевания было более благоприятным - у менышего числа больных отмечались клинические признаки выраженной сократительной дисфункции левого желудочка (сердечная недостаточность, стойкая артериальная гипотензия и кардиогенный шок), атриовентрикулярные блокады высокой степени, асистолия, а также серьезные аритмии (фибрилляция желудочков, мерцание и трепетание предсердий). Таким образом, очевидно, что алтеплаза превосходит стрептокиназу по эффективности и в целом ожидаемая польза заметно превосходит небольшое увеличение частоты внутричерепных кровотечений.

Тенектеплаза - производное алтеплазы, полученное с помощью генной инженерии. Этот препарат вводится внутривенно болюсом и по сравнению с алтеплазой обладает большей фибрин-специфичностью. Чтобы проверить гипотезу о не меньшей эффективности (эквивалентности) болюсного введения тенектеплазы по сравнению с 1,5-часовой инфузией алтеплазы в стационаре (при сочетании каждого из режимов тромболитической терапии с использованием ацетилсалициловой кислоты и внутривенной инфузией нефракционированного гепарина на протяжении как минимум 48 ч), было спланировано исследование ASSENT-2 [26]. В него было рандомизировано 16949 больных ИМ с подъемами сегмента ST на ЭКГ в первые 6 ч после начала заболевания. По общей смертности за 30 сут. группы больных, получавших тенектеплазу и алтеплазу, достоверно не различались ни через месяц, ни через год [27]. При учете несмертельных осложнений заболевания оказалось, что при использовании тенектеплазы меныше больных имели выраженные проявления сердечной недостаточности (6,1 против 7,0\%; $\mathrm{p}=0,026)$ и подверглись операции коронарного шунтирования $(5,5$ против $6,2 \% ; p=0,049)$. По частоте внутричерепных кровотечений группы тенектеплазы и алтеплазы заметно не различались, однако у лиц с наиболее высоким риском этого осложнения (пожилые женщины с массой тела не выше 67 кг) тенектеплаза превосходила алтеплазу (1,1 против 3,0\%; $\mathrm{p}<0,05)$. Кроме того, у получавших тенектеплазу достоверно реже возникали невнутричерепные кровотечения (26,4 против 28,9\%, $p=0,0003$ в целом; 4,7 против 5,9\%, $p=0,0002$ для крупных кровотечений; 21,7 против 22,9\% для незначительных кровотечений, $\mathrm{p}=0,055$ соответственно). В результате в группе тенектеплазы реже требовалось переливание крови (4,2 против 5,5\%, р = 0,0002). Таким образом, тенектеплаза оказалась эквивалентной алтеплазе по влиянию на смертность, но имела преимущество в простоте использования на практике (однократный внутривенный болюс вместо 1,5-часовой инфузии с меняющейся скоростью) и безопасности (способности вызывать по крайней мере невнутричерепные кровотечения).

Прямого сопоставления тенектеплазы и стрептокиназы в достаточно крупном клиническом испытании не проводилось. По косвенным данным тенектеплаза превосходит стрептокиназу по эффективности. Однако судить об их сравнительной безопасности не представляется возможным.
Крупных исследований с клиническими конечными точками по сопоставлению стрептокиназы и фибринспецифических фибринолитиков в сроки, заметно превышающие 6 ч после начала ИМ с подъемами сегмента ST на ЭКГ, не проводилось. Однако есть ангиографические свидетельства, что фибрин-специфичные препараты могут иметь преимущество в әффективности и в поздние сроки тромботической окклюзии коронарной артерии. Так, по данным рандомизированного двойного слепого ангиографического исследования TIMI-1, включавшего 290 больных, проходимость коронарной артерии через 90 мин после начала инфузии алтеплазы не зависела от времени начала лечения, в то время как әффективность стрептокиназы заметно уменышалась в случаях, когда от появления симптомов до введения препарата прошло больше 4 ч [28].

\section{Международным сообществом при остром коронарном синдроме со стойкими подъемами сегмента ST на ЭКГ рекомендованы стрептокиназа, алтеплаза, тенектеплаза и ретеплаза (последняя в РФ не зарегистрирована)}

В целом на сегодняшний день очевидно, что использование современных фибрин-специфичных фибринолитиков (алтеплазы, тенектеплазы) позволяет повысить эффективность тромболитической терапии, а тенектеплаза заметно упрощает лечение и имеет преимущество перед алтеплазой по безопасности. Кроме того, у стрептокиназы есть ряд особенностей, способных создать дополнительные клинические проблемы. В частности, она иммуногенна, и образовавшиеся антитела могут присутствовать в крови очень долго (вплоть до 10 лет). Это делает нежелательным повторное применение стрептокиназы, особенно в ближайшие несколько лет. Кроме того, при ее введении возможно образование брадикинина, приводящее к снижению АД (иногда очень существенному), что может потребовать по меньшей мере уменьшения скорости или приостановки инфузии препарата. Очевидно, с точки зрения әффективности такое вынужденное затягивание сроков поступления полной дозы фибринолитика в организм нежелательно. Этих недостатков лишены как алтеплаза, так и тенектеплаза.

\section{СОПУТСТВУЮЩАЯ ТЕРАПИЯ}

Результаты клинических испытаний, выполненных в последние несколько лет, показали, что улучшить течение заболевания после тромболитической терапии можно при совершенствовании сопутствующего лечения. Так, оказалось, что дополнительную пользу приносит более активное воздействие на функциональную активность тромбоцитов за счет одновременного применения ацетилсалициловой кислоты и клопидогрела. По данным крупнейшего двойного слепого плацебо-контролируемого исследования COMMIT/ CCS-2, включавшего 45852 больных без ограничения возрас- 
та, применение клопидогрела вплоть до 4-й недели заболевания или более ранней выписки (в среднем 2 недели) позволяло дополнительно предотвратить 9 неблагоприятных исходов (смерть, рецидив ИМ или инсульт) на каждую тысячу леченых больных [29]. Этот эффект был достигнут за счет достоверного уменышения общей смертности (6 на каждую тысячу леченых больных) и рецидивов ИМ (3 на каждую тысячу леченых). Характерно, что он оказался сопоставимым по величине с клиническим преимуществом алтеплазы перед стрептокиназой, что в итоге привело к повсеместному вытеснению последней из широкого практического использования в странах, где это возможно экономически. Такое кратковременное использование клопидогрела оказалось достаточно безопасным - частота серьезных кровотечений не увеличилась. При этом положительный эффект отмечен как у больных, получивших фибринолитик, так и у оставшихся без реперфузионного лечения. Результаты исследования CLARITY-TIMI 28 позволяют ожидать пользы подобного и при инвазивном подходе к ведению больных после тромболитической терапии (коронарная ангиография в первую неделю заболевания с реваскуляризацией миокарда - в основном стентированием - при соответствующих показаниях) [30, 31]. Наиболее вероятный механизм, лежащий в основе раннего клинического эффекта добавления клопидогрела к ацетилсалициловой кислоте, - уменышение частоты сохраняющегося тромбоза коронарной артерии и риска ее повторной окклюзии $[30,32]$.

Улучшить клиническое течение заболевания после тромболитической терапии позволяют и современные антикоагулянты. Результаты, полученные в последние годы, показали, что больным без исходно высокого риска кровотечений и существенного увеличения уровня креатинина в крови дополнительную пользу приносит продление парентерального введения антикоагулянтов вплоть до 1 недели (или выписки из стационара, если она произошла раньше) [33-35].

Так, в крупном контролируемом исследовании ExTRACTTIMI 25 1-недельное использование эноксапарина в дозе, подобранной по массе тела больного и скорригированной в соответствии с возрастом и клиренсом креатинина, по сравнению со стандартной 48-часовой инфузией нефракционированного гепарина, способствовало снижению риска смерти и несмертельного ИМ в ближайший месяц на 17\%, что соответствовало предотвращению 21 такого события на каждую тысячу леченых [34]. Это положительное влияние заметно превосходило риск геморрагических осложнений (дополнительное возникновение 7 крупных несмертельных и невнутричерепных кровотечений на каждую тысячу леченых больных) и распространялось как на случаи применения стрептокиназы, так и фибрин-специфичных фибринолитиков [35]. По-видимому, в основе эффективности данного подхода лежит предотвращение повторной окклюзии артерии, кровоснабжающей зону ИМ, что может быть связано как с преимуществом эноксапарина как такового (положительное влияние на частоту рецидивов ИМ отмечено уже в первые 48 ч после начала лечения), так и с большей длительностью лечения (предотвращением реактивации тромбообразования после отмены антикоагулянта) [34, 36].

В крупном контролируемом исследовании OASIS-6 1-недельное введение фондапаринукса после тромболитической терапии не фибрин-специфичным фибринолитиком (в основном стрептокиназой) по сравнению с плацебо, которое получали 96,4\% больных, способствовало снижению риска смерти или ИМ в ближайший месяц на 24\%, что соответствовало предотвращению 31 такого события на каждую тысячу леченых $[37,38]$. При этом применявшаяся доза фондапаринукса (2,5 мг 1 раз в сутки) была достаточно безопасной частота крупных кровотечений не только не увеличилась, но и оказалась достоверно меньшей, чем в группе сравнения. Число больных, получивших фибрин-специфичные фибринолитики, в исследовании OASIS-6 было небольшим (875 человек). Наряду с этим большинство из них $(97,7 \%)$ получали 48-часовую инфузию нефракционированного гепарина. В этой подгруппе фондапаринукс не обладал преимуществом в эффективности.

Применение современных антикоагулянтов решает еще одну проблему, возникающую при тромболитической терапии, которая связана с необходимостью внутривенной инфузии нефракционированного гепарина на протяжении ближайших 48 ч, требующей подбора дозы препарата под контролем активированного частичного тромбопластинового времени. Так, низкомолекулярные гепарины и фондапаринукс вводят под кожу живота. Для выбора дозы необходимо знать массу тела больного (если применяются низкомолекулярные гепарины) и рассчитать клиренс креатинина или скорость клубочковой фильтрации (при значениях ниже 30 необходимо уменышить дозу эноксапарина, фондапаринукс официально противопоказан при клиренсе креатинина ниже 20). В настоящее время общепринятой является точка зрения, что в большинстве случаев контроля воздействия этих ЛС на процесс свертывания крови во время лечения не требуется [39].

\section{Тенектеплаза - производное алтеплазы, полученное с помощью генной инженерии, по сравнению с алтеплазой обладает больщей фибрин-специфичностью}

Вместе с тем существуют больные с исходно высоким риском клинически значимых кровотечений, когда на первый план выходит безопасность лечения. Представляется, что в этой ситуации разумно рассматривать применение стрептокиназы без антикоагулянтов (если к ним нет других показаний) или ее сочетание с 24-48-часовой инфузией нефракционированного гепарина, а при введении фибринспецифичных фибринолитиков (предпочтительно тенектеплазы) - следует говорить о 24-48-часовой инфузии нефракционированного гепарина. Можно также обсуждать краткосрочное применение эноксапарина или фондапаринукса, однако такие подходы не изучены. 


\section{Таблица. Выбор антиагрегантов и антикоагулянтов при тромболитической терапии у больных с острым коро-} нарным синдромом и со стойкими подьемами сегмента ST на ЭКГ

\begin{tabular}{|c|c|}
\hline $\begin{array}{l}\text { Подход к лечению в ранние } \\
\text { сроки заболевания }\end{array}$ & Антитромботическая терапия \\
\hline Тромболитическая терапия & Ацетилсалициловая кислота + клопидогрел + антикоагулянт \\
\hline - стрептокиназа & $\begin{array}{l}\text { - оптимально: подкожные инъекции фондапаринукса или эноксапарина до } 8 \text { сут., более ран- } \\
\text { ней выписки из стационара или успешного ЧКВ } \\
\text { - при существенно нарушенной функции почек, высоком риске кровотечения: внутривенная } \\
\text { инфузия нефракционированного гепарина в течение 24-48 ч с подбором дозы под контро- } \\
\text { лем АЧТВ или отказ от использования антикоагулянтов }\end{array}$ \\
\hline - алтеплаза или тенектеплаза & $\begin{array}{l}\text { - оптимально: подкожные инъекции эноксапарина до } 8 \text { сут., более ранней выписки из стацио- } \\
\text { нара или успешного ЧкВ } \\
\text { - при существенно нарушенной функции почек, высоком риске кровотечения: внутривенная } \\
\text { инфузия нефракционированного гепарина в течение 24-48 ч с подбором дозы под контро- } \\
\text { лем АЧТВ }\end{array}$ \\
\hline - проурокиназа рекомбинантная & $\begin{array}{l}\text { внутривенная инфузия нефракционированного гепарина в течение 24-48 ч с подбором дозы } \\
\text { под контролем АЧТВ }\end{array}$ \\
\hline Первичное ЧКВ & $\begin{array}{l}\text { ацетилсалициловая кислота + прасугрел, тикагрелор или клопидогрел + во время процедуры } \\
\text { внутривенные болюсы нефракционированного гепарина под контролем активированного вре- } \\
\text { мени свертывания крови или внутривенная инфузия бивалирудина или внутривенные болюсы } \\
\text { эноксапарина; в отдельных случаях процедуру выполняют на фоне внутривенного введения } \\
\text { блокаторов гликопротеина IIb/IIIа тромбоцитов }\end{array}$ \\
\hline Без реперфузионного лечения & $\begin{array}{l}\text { ацетилсалициловая кислота + клопидогрел + подкожные инъекции фондапаринукса до } 8 \text { сут., } \\
\text { более ранней выписки из стационара или успешного ЧКВ, если нет существенно нарушенной } \\
\text { функции почек, высокого риска кровотечения }\end{array}$ \\
\hline
\end{tabular}

Подходы к выбору антиагрегантов и антикоагулянтов в дополнение к разным фибринолитикам у больных с острым коронарным синдромом и стойкими подъемами сегмента ST на ЭКГ представлены в таблище.

\section{ЗАКЛЮЧЕНИЕ}

Несмотря на более высокую әффективность чрескожных коронарных вмешательств в лечении больных с остро возникшей тромботической окклюзией коронарной артерии (развивающимся ИМ с подъемами сегмента ST на ЭКГ), не утрачивает своего значения и тромболитическая терапия, основные преимущества которой - доступность и возможность начать лечение незамедлительно после постановки диагноза. Улучшить клинические исходы после тромболитической терапии позволяет выбор наиболее эффективного и/или безопасного фибринолитика (алтеплазы, тенектеплазы), одновременное применение антиагрегантов (сочетания ацетилсалициловой кислоты и клопидогрела) и достаточно длительное использование антикоагулянтов (фондапаринукса, эноксапарина). Современные фибринолитики (тенектеплаза) и антикоагулянты позволяют также предельно упростить лечение.

\section{ЛИТЕРАТУРА}

1. Диагностика и лечение больных острым инфарктом миокарда с подъемами сегмента ST ЭКГ. Рекомендации Всероссийского научного общества кардиологов // Кардиоваскулярная терапия и профилактика. 2007. №6(8). Прил. 1.

2. Goodman S.G., Menon V., Cannon C.P. et al. Acute ST-Segment Elevation Myocardial Infarction. American College of Chest Physicians Evidence-Based Clinical Practice Guidelines (8th Edition) // Chest. 2008. №133. 708S-775S.

3. 2007 Focused Update of the ACC/AHA 2004 Guidelines for the Management of Patients With ST-Elevation Myocardial Infarction. A Report of the American College of Cardiology/American Heart Association Task Force on Practice Guidelines // JACC. 2008. №51. P. 210-247.

4. 2013 ACCF/AHA Guideline for the Management of ST-Elevation Myocardial Infarction. A Report of the American College of Cardiology Foundation/American Heart Association Task Force on Practice Guidelines // JACC. 2013. №61. P. 485-510.

5. ESC Guidelines for the management of acute myocardial infarction in patients presenting with ST-segment elevation. The Task Force on the management of ST-segment elevation acute myocardial infarction of the European Society of Cardiology (ESC) // Eur. Heart J. 2012. №33. P. 2569-2619.

6. ISIS-2 (Second International Study of Infarct Survival) Collaborative Group. Randomised trial of intravenous streptokinase, oral aspirin, both, or neither among 17,187 cases of suspected acute myocardial infarction: ISIS-2 // Lancet. 1988. №13 August. P. 349-360.

Полный список литературы вы можете запросить в редакции. 